\title{
Strategic Inter-Regional Transfers
}

\author{
Jean Hindriks \\ University of London, Queen Mary and Westfield College \\ and \\ Gareth D. Myles \\ University of Exeter
}

July 2000

\begin{abstract}
In this paper we derive the equilibrium level of redistribution from one mobile factor (say, the rich or capital) to another possibly mobile factor (say, the poor or labour) when regions choose both their inter-regional transfers and redistributive policies non-cooperatively. We find that interregional transfers are always desirable (to mitigate the fiscal competition), but cannot be sustained (as a Nash equilibrium) when chosen simultaneoulsy with the redistributive policy. On the other hand if regions can precommit to inter-regional transfers before setting their redistributive policy, the strategic effect of inter-regional transfers makes them sustainable. However there are also equilibria with partial or no inter-regional transfers at all. The effects of regional asymmetries are analyzed. Interestingly enough, evidence suggests that predictions of our model accord very closely with the pattern of transfers in the EU across member states.
\end{abstract}

JEL classification. C72, D62, H77, R50.

Keywords. inter-regional transfers, mobility externality, redistribution.

Mailing address: Jean Hindriks, Department of Economics, Queen Mary and Westfield College, University of London, Mile End Road, London E1 4NS, UK. 


\section{Introduction}

Decentralization has some obvious advantages in terms of accountability, information and the idea of a government closer to the people is usually regarded as desirable. But decentralization also brings with it the fiscal externality problem. Fiscal externality arises whenever regions choose independently some tax or regulation policy (to promote competition or to achieve some environmental, social or quality standards). This results in severe loss for all if the taxed or regulated factor is very mobile. For example if international capital mobility is high, each region competes to attract capital and this leads to a situation with little capital income taxation, even if each region would like high capital taxation for public good provision and redistribution reasons. ${ }^{1}$ Similarly, the increasing mobility of individuals can limit the capacity of regions to redistribute from the rich to the poor as this may drive out the rich and attract the poor. This fiscal externality problem is serious in the current EU context where the ongoing economic integration decreases mobility costs.

The existing literature on the subject provides several solutions to this problem. The most obvious solution (fiscal federalism) is the centralization of fiscal policy. However, diversity of local preferences undermines the case for centralization (see Oates, 1972), and it can even be argued that centralization is not desirable at all when preferences are too heterogenous (Pauly, 1973). Another solution (Pigovian corrective taxation), is to design corrective schemes at the federal level that aim to internalize the fiscal externalities that the local regions inflict on each other in setting their fiscal policies. Examples of such corrective schemes are federal matching grants to the payments to the poor made by regions and federal transfers to local regions according to the number of poor residents (see e.g., Boadway and Flatters, 1982; or Krelove, 1992).

The implementation of these mechanisms is obviously problematic (mostly for informational reason) and has led some authors to propose a more decentralized solution. ${ }^{2}$ This solution, building on the seminal work of Myers (1990), challenges the need for central government intervention. The idea is that there exist Nash-equilibrium inter-regional transfers that can reach the same outcome as central government intervention. Myers shows the ef-

\footnotetext{
${ }^{1}$ A specific but suggestive example of capital mobility is the use of transfer pricing by BMW to escape the high corporation tax in Germany: in 1988, BMW reported $88 \%$ of its profits in Germany, but by 1992 , the proportion had fallen to only $5 \%$.

${ }^{2}$ See Piketty (1996) for a critical assessment of this pigovian corrective tax solution. Consideration of asymmetric information between central and regional governments in the design of grants from central government can be found in Bucovestky et al (1998) and Lockwood (1999)
} 
ficiency of inter-regional transfers in a representative agent economy with perfect labour mobility and local public goods. The point is that interregional transfers can discourage migrations that depress wages. Hence, voluntary inter-regional transfers would be made as part of an equilibrium entry-deterrence behavior. An important caveat of this analysis is the assumption that individuals are identical which precludes the consideration of any redistributive issues. Another key assumption is perfect labour mobility. Indeed, Wellish (1994) shows that central intervention may again be needed if individuals are imperfectly mobile. (Mansoorian and Myers (1993) however find that efficient Nash-equilibrium interregional transfers can be recovered with imperfect mobility if there is enough asymmetry between the regions. $)^{3}$

The purpose of this paper is to analyze the sustainability of inter-regional transfers and the effect they have on the equilibrium level of redistribution when the economy is populated by a large set of individuals who differ in their income level and their mobility. We concentrate on the strategic motive for inter-regional transfers and ignore the fact that they can also be used to prevent wage depressing in-migrations (although we consider the fact that migration of the poor can depress transfer payments) or to share local risks. This paper starts from the assumption that each region abides de facto to the free movement and equal treatment principles (i.e, unrestricted mobility). ${ }^{4}$ Building on this assumption, we argue that redistribution at the local level is possible without central government intervention and that there exists (subgame perfect) Nash-equilibrium inter-regional transfers that can reach the same outcome as fiscal centralization. However there also exist (subgame perfect) Nash equilibria with only partial or no inter-regional transfers at all. ${ }^{5}$

We develop a simple model to establish these results. The purpose of this minimalist modelling approach is to make the logic behind the results sufficiently clear to convince the reader of their validity in more general environments. Throughout we shall adopt the policy-based approach to fiscal competition games: this takes the policies of other regions as fixed, in con-

\footnotetext{
${ }^{3}$ To be complete, we should also mention the bargaining solution to the fiscal externality problem. According to this solution governments should realize that fiscal competition results into an inefficiency and should therefore directly cooperate. However, we believe that imperfections in the bargaining process (in the form of imperfect information) and the political opportunism of short-lived politicians will almost certainly prevent the emergence of an efficient solution.

${ }^{4}$ This is consistent with for example the Treaty of Rome (articles 48 and 51), the U.S. Constitution, the Canadian Charter of Rights and Freedom (Constitution Act of 1982)

${ }^{5}$ Besides internalizing inter-regional spillovers, inter-regional transfers can also be used for insurance motive (see Lockwood (1999), Persson and Tabellini (1996a,b) for the optimal design by a central government of inter-regional transfers.
} 
trast to the membership-based equilibrium which takes the memberships of regions as fixed (see Caplin and Nalebuff, 1997). So in the policy-based approach (like Epple and Romer, 1991), individuals move after the policy choices are made while in the membership-based approach residential choices precede policy choices. ${ }^{6}$ We suppose a fixed number of regions. Individuals differ both in their income and their preference for regional location. Each region abides by the free movement and equal treatment principles (i.e., unrestricted mobility) and chooses its policy taking the policy of the other as given. Intra-regional redistributive policies transfer resources (vertically) from the rich residents to the poor residents. Inter-regional transfers transfer resources (horizontally) between regions. Both the rich and the poor are mobile, but we also assume that they have preferences for location which reduce their mobility. To keep the analysis tractable, we abstract from the production side and assume that individuals have fixed income (no incentive effect). In this context adopting the membership based approach is not interesting because setting policies after the residential choice are made removes any fiscal competition from the analysis.

The results of the analysis show that inter-regional transfer cannot be sustained when transfer and redistributive policy are chosen simultaneously. But observation of the EU (some figures are given in Section 5) shows that transfers are prominent. ${ }^{7}$ The analysis we offer shows that transfers are supported through their strategic effects on the setting of redistributive taxes. This result holds true even with regional asymmetries and can be interpreted in two ways. Firstly, it can be treated as an explanation of why transfers exist in the EU. The evidence we present shows that the pattern of transfers in the EU across member states accords very closely with the predictions of the model. Of course, this is not a formal test but it is suggestive none the less. Secondly, the result can be taken as guidance on how a federal system should determine its fiscal affairs. That is, if transfers are to be set through negotiations, as they are in the EU, this is best done prior to the members setting their tax rates. In this way, inter-regional transfers can be sustained without recourse to a central authority.

The paper is organised as follows. Section 2 describes the fiscal competition game and the equilibrium concept used. Section 3 derives the symmetric equilibria of the game when inter-regional and intra-regional policies are chosen simultaneously. Section 4 derives the symmetric equilibria when

\footnotetext{
${ }^{6}$ See Hansen and Kessler (1998) for the membership-based approach to inter-regional transfers. Paradoxicaly in their model, regional transfers promote regional inequality.

${ }^{7}$ As for illustration, Hansen and Kessler (1998) report that the EU interstate transfer system, Regional Funds, represented about 1/4 of the total EU budget in 1993. In Germany, inter-regional transfers organized through the Landerfinanzausgleich system, represented a total of 50 billion DM in 1996.
} 
inter-regional transfers are chosen before the intra-regional policies. Section 5 investigates the effects of regional asymmetries on the results and present evidence on the pattern of transfers across EU member states. Section 6 concludes the paper.

\section{The Model}

The model we use is adapted from Hindriks (1999). There are two exogenously given regions, called the West and East regions for sake of definiteness. We refer to the East region by the use of the superscript $\left(^{*}\right)$. The two regions are symmetric in a sense we shall make precise shortly. Regional asymmetries are introduced in Section 5. The population is divided into two income groups and income is taken to be fixed. The two income levels are normalized to 0 and 1 . There is a continuum of poor individuals (whose income is equal to 0 ) with a mass of $n_{1}$, and there is a continuum of rich individuals (whose income is equal to 1 ) with a mass of $n_{2}$. The relative mass of rich individuals in the economy is denoted by $\rho \equiv \frac{n_{2}}{n_{1}}$. Of course rich and poor groups are a metaphor to represent, respectively, the net contributors and the net beneficiaries from the redistributive policy. Within each income group, the preference for regional location can be described by a single taste parameter $x \in[0,1]$. Those with low $x$ prefer the West region, those with high $x$ prefer the East region and those in the middle are indifferent. We further make the simplifying (but innocuous) assumption that $x$ is uniformly distributed within each class (i.e., rich and poor).

The regions impose taxes $T$ and $T^{*}$ (with $0 \leq T, T^{*} \leq 1$ ) on their rich residents, and transfer fraction $\alpha$ and $\alpha^{*}$ of their tax revenue to the other region(with $0 \leq \alpha, \alpha^{*} \leq 1 / 2$ ); the rest is used to pay a transfer $B$ and $B^{*}$ to their poor residents. ${ }^{8}$ Given the policy choices, each individual freely joins the region that maximises his utility. Since there is a continuum of individuals, we can avoid the so-called integer problem (see Wooders, 1978) due to the discontinuous jumps in the payoffs induced by individuals' moves from one region to another. Each region is constrained to have a balanced budget, so the set of feasible tax-transfer policies that each region can afford to offer depends on who they attract. Furthermore, who they attract depends on their policy choices. Let $z=(T, B, \alpha), z^{*}=\left(T^{*}, B^{*}, \alpha^{*}\right)$, then each region selects a feasible policy

$$
z \in Z\left(S\left(z, z^{*}\right)\right)
$$

\footnotetext{
${ }^{8}$ Note that if both regions choose $\alpha=\alpha^{*}=1 / 2$ they will face the same tax base and the fiscal externality problem will disappear. Because of the symmetry between regions, we ignore situations where some regions share more than one half of their tax revenue while others share less than one half.
} 


$$
z^{*} \in Z\left(S^{*}\left(z, z^{*}\right)\right)
$$

where $\left\{S\left(z, z^{*}\right), S^{*}\left(z, z^{*}\right)\right\}$ is the division of the population between the two regions that will result from the policy profile $z, z^{*}$, and $Z$ is the set of taxtransfer policies that break even given the composition of the region.

Individuals care only about their net income and their location. The payoff of a poor individual with preference $x \in[0,1]$ is

$$
\begin{aligned}
U_{1}\left(z, z^{*}, x\right) & =B-d_{1} x \quad \text { in the West region } \\
U_{1}^{*}\left(z, z^{*}, x\right) & =B^{*}-d_{1}(1-x) \quad \text { in the East region, }
\end{aligned}
$$

where $d_{1}>0$ measures the degree of attachment to location of the poor. So, a higher degree of attachment is akin to lower mobility. Each poor individual with $x$ such that $U_{1}\left(z, z^{*}, x\right) \geq U_{1}^{*}\left(z, z^{*}, x\right)$ joins the West region.

The payoff of a rich individual with preference $x \in[0,1]$ is

$$
\begin{aligned}
U_{2}\left(z, z^{*}, x\right) & =(1-T)-d_{2} x \quad \text { in the West region } \\
U_{2}^{*}\left(z, z^{*}, x\right) & =\left(1-T^{*}\right)-d_{2}(1-x) \quad \text { in the East region, }
\end{aligned}
$$

where the parameter $d_{2}>0$ measures the degree of attachment to location of the rich. Each rich individual with preference $x$ such that $U_{2}\left(z, z^{*}, x\right) \geq$ $U_{2}^{*}\left(z, z^{*}, x\right)$ joins the West region. We shall assume that the degree of attachment is not too high $\left(d_{2}<1\right)$ so that regions are indeed competing to attract the rich. Hence, $d_{2} \in(0,1)$. Note that their degree of attachment (and thus their degree of mobility) can be different from the poor. Let $d=\frac{d_{2}}{d_{1}}$ denote the relative attachment of the rich or, equivalently, the relative mobility of the poor. So if $d<1$ the rich are less attached to location and thus more mobile than the poor, and vice versa. Note that the model can accomodate arbitrarily low mobility of the poor (by setting $d_{1}$ sufficiently high).

Given these individual payoff functions, any policy configuration $\left(z, z^{*}\right)$ induces the following partition of the population between the two regions

$$
\begin{aligned}
S\left(z, z^{*}\right) & =\times_{i=1,2}\left\{x \in[0,1]: U_{i}\left(z, z^{*}, x\right) \geq U_{i}^{*}\left(z, z^{*}, x\right)\right\} \\
S^{*}\left(z, z^{*}\right) & =\times_{i=1,2}\left\{x \in[0,1]: U_{i}\left(z, z^{*}, x\right)<U_{i}^{*}\left(z, z^{*}, x\right)\right\} .
\end{aligned}
$$

The equilibrium concept is the non-cooperative Nash equilibrium. The strategic variables are tax rates, $\left(T, T^{*}\right) \in[0,1]^{2}$, and tax shares $\left(\alpha, \alpha^{*}\right) \in$ $[0,1 / 2]^{2}$. The benefit levels $\left(B, B^{*}\right)$ are adjusted automatically according to the resulting migrations to maintain budget balance. Each region sets its policy to maximize the income of its poor residents, given the policy 
of the other region. Regions are fully aware of the migration effects of their policy choices. Equilibrium is a fixed-point in which no individual wishes to switch region, no region wishes to switch policy, and the budget is balanced. We denote by $B\left(T, T^{*}, \alpha, \alpha^{*}\right)$ and $B^{*}\left(T, T^{*}, \alpha, \alpha^{*}\right)$ the transfer levels in both regions that result from the tax pair $\left(T, T^{*}\right)$ and tax shares $\left(\alpha, \alpha^{*}\right)$. Substituting these transfer functions into the payoff functions, we obtain that for each strategy profile $\left(T, T^{*}, \alpha, \alpha^{*}\right)$ and for each class $i$ (with $i=1,2)$, there exists $x_{i}\left(T, T^{*}, \alpha, \alpha^{*}\right) \in[0,1]$ such that all individuals in class $i$ with preference $x \leq x_{i}\left(T, T^{*} \alpha, \alpha^{*}\right)$ join the West region and all individuals in class $i$ with preference $x>x_{i}\left(T, T^{*} \alpha, \alpha^{*}\right)$ join the East region. Hence, $S\left(T, T^{*}, \alpha, \alpha^{*}\right)=\times_{i=1,2}\left\{x \in[0,1]: x \leq x_{i}\left(T, T^{*}, \alpha, \alpha^{*}\right)\right\}$ and $S^{*}\left(T, T^{*}, \alpha, \alpha^{*}\right)=\times_{i=1,2}\left\{x \in[0,1]: x>x_{i}\left(T, T^{*}, \alpha, \alpha^{*}\right)\right\}$. Since $x$ is uniformly distributed over $[0,1]$ among each class $i(i=1,2), x_{i}\left(T, T^{*}, \alpha, \alpha^{*}\right)$ is also the percentage of individuals in class $i$ who join the West region and $1-x_{i}\left(T, T^{*}, \alpha, \alpha^{*}\right)$ is the percentage of individuals in class $i$ who join the East region. Therefore, the budget balance requirement in each region reduces to

$$
B\left(T, T^{*}, \alpha, \alpha^{*}\right)=\rho \frac{(1-\alpha) T x_{2}\left(T, T^{*}, \alpha, \alpha^{*}\right)+\alpha^{*} T^{*}\left(1-x_{2}\left(T, T^{*}, \alpha, \alpha^{*}\right)\right)}{x_{1}\left(T, T^{*}, \alpha, \alpha^{*}\right)}
$$

and,

$$
B^{*}\left(T, T^{*}, \alpha, \alpha^{*}\right)=\rho \frac{\left(1-\alpha^{*}\right) T^{*}\left(1-x_{2}\left(T, T^{*}, \alpha, \alpha^{*}\right)\right)+\alpha T x_{2}\left(T, T^{*}, \alpha, \alpha^{*}\right)}{1-x_{1}\left(T, T^{*}, \alpha, \alpha^{*}\right)} .
$$

This completes the description of the game. The game is symmetric, in the sense that if $T=T^{*}$ and $\alpha=\alpha^{*}$ then we have $B=B^{*}$ and $x_{1}()=$. $x_{2}()=.\frac{1}{2}$, that is, the rich and the poor are equally divided between the two regions. We now derive the equilibria of this game. First we consider the case where taxes and tax shares are chosen simultaneously and derive the symmetric Nash equilibrium. Then we analyse the case where tax shares are chosen before taxes and derive the symmetric Nash equilibrium. The equilibrium concept is the same in both cases: (perfect) Nash equilibrium. The games simply differ in their timing. In the sequential game, regions have a chance to choose their inter-regional transfers before taxes and, therefore, to influence the tax stage.

\section{Simultaneous taxes and inter-regional transfers}

In the simultaneous move game, each region sets its tax and tax share taking as given the policy choice of the other, anticipating correctly the induced migration and the resulting transfer levels. Since the income of every poor resident is increasing in the transfer level of his own jurisdiction, a good 
candidate for equilibrium is the transfer maximising tax rate. Therefore, given $T^{*}$ and $\alpha^{*}$, the West region solves

$$
\operatorname{Max}_{(\alpha, T)} B\left(T, T^{*}, \alpha, \alpha^{*}\right)
$$

where $B\left(T, T^{*}, \alpha, \alpha^{*}\right)$ is given by the budget balance requirement (1). To solve this optimization problem, we first derive the migration response of each class to a tax change. Since we look for a symmetric equilibrium, we can reasonably ignore the corner problems and focus on interior migration responses.

Given the policy choices $\left(T, T^{*}, \alpha, \alpha^{*}\right)$, with $T$ close to $T^{*}$ and $\alpha$ close to $\alpha^{*}$, the equilibrium migration of the rich is characterized by the marginal individual with preference $x=x_{2}\left(T, T^{*}, \alpha, \alpha^{*}\right)$ who is indifferent between the two regions, so $x=x_{2}\left(T, T^{*}, \alpha, \alpha^{*}\right)$ solves

$$
(1-T)-d_{2} x=\left(1-T^{*}\right)-d_{2}(1-x)
$$

This yields

$$
x_{2}\left(T, T^{*}, \alpha, \alpha^{*}\right)=\frac{1}{2}+\frac{T^{*}-T}{2 d_{2}}
$$

Since $x_{2}\left(T, T^{*}, \alpha, \alpha^{*}\right)$ is independent of $\left(\alpha, \alpha^{*}\right)$ we can write $x_{2}\left(T, T^{*}\right)=$ $x_{2}\left(T, T^{*}, \alpha, \alpha^{*}\right)$. Therefore all the rich with $x \leq x_{2}\left(T, T^{*}\right)$ go to the West region and all the rich with $x>x_{2}\left(T, T^{*}\right)$ go to the East region. Given the uniform distribution, $x_{2}\left(T, T^{*}\right)$ determines also the fraction of the rich who choose to reside in the West region. We verify that $x_{2}\left(T, T^{*}\right)=1 / 2$ for $T=T^{*}$ (due to the symmetry of the model) and that $x_{2}\left(T, T^{*}\right)$ is decreasing in $T$ and increasing in $T^{*}$. This reflects the fact that the rich prefer to join the region with a lower tax rate. The migration response of the rich to a small tax change from $T=T^{*}$ in the West region is

$$
\left[\frac{d x_{2}\left(T, T^{*}\right)}{d T}\right]_{T=T^{*}}=-\frac{1}{2 d_{2}}
$$

Thus, the migration response of the rich to a marginal tax change is decreasing with their attachment to location.

Given the policy choices $\left(T, T^{*}, \alpha, \alpha^{*}\right)$ with $T$ close to $T^{*}$ and $\alpha$ close to $\alpha^{*}$ the utility of the poor individual with preference $x$ is

$u_{1}\left(T, T^{*}, \alpha, \alpha^{*} ; x\right)=B\left(T, T^{*}, \alpha, \alpha^{*}\right)-d_{1} x$ in the West region

and

$u_{1}^{*}\left(T, T^{*}, \alpha, \alpha^{*} ; x\right)=B^{*}\left(T, T^{*}, \alpha, \alpha^{*}\right)-d_{1}(1-x)$ in the East region. 
The equilibrium migration of the poor is characterized by the marginal individual with preference $x=x_{1}\left(T, T^{*}, \alpha, \alpha^{*}\right)$ who is indifferent between the two regions. Using (1) and (2), $x=x_{1}\left(T, T^{*}, \alpha, \alpha^{*}\right)$ solves

$$
\begin{aligned}
& \rho\left[\frac{(1-\alpha) T x_{2}\left(T, T^{*}\right)+\alpha^{*} T *\left(1-x_{2}\left(T, T^{*}\right)\right)}{x}\right]-d_{1} x= \\
& \rho\left[\frac{\left(1-\alpha^{*}\right) T^{*}\left(1-x_{2}\left(T, T^{*}\right)\right)+\alpha T x_{2}\left(T, T^{*}\right)}{1-x}\right]-d_{1}(1-x) .
\end{aligned}
$$

Given the uniform distribution, $x=x_{1}\left(T, T^{*}, \alpha, \alpha^{*}\right)$ determines also the fraction of the poor who join the West region. Notice that the equilibrium migration of the poor, $x_{1}\left(T, T^{*}, \alpha, \alpha^{*}\right)$ depends on the equilibrium migration of the rich, $x_{2}\left(T, T^{*}\right)$.

Using the implicit function theorem together with (5) and the symmetry of the model, we obtain

$$
\left[\frac{d x_{1}}{d T}\right]_{z=z^{*}}=\frac{(1-2 \alpha)\left(1-\frac{2 T}{d_{2}}\right) \rho}{2 d_{1}+4 \rho T}
$$

It is worth noting that $\left[d x_{1}\left(T, T^{*}\right) / d T\right]_{z=z^{*}}<0$ for $T>d_{2} / 2$. The reason is that when the rich are highly mobile (low $d_{2}$ ), a tax increase induces so many rich to leave that the poor find it profitable to chase them.

We are now in a position to characterize the equilibrium policy choices. Given $T^{*}$ and $\alpha^{*}$, the West region solves

$$
\operatorname{Max}_{(T, \alpha)} B\left(T, T^{*}, \alpha, \alpha^{*}\right)
$$

Differentiating $B\left(T, T^{*}, \alpha, \alpha^{*}\right)$ with respect to $T$ around $z=z^{*}$ and using the symmetry of the model together with (5) and (7), we have

$$
\begin{aligned}
{\left[\frac{d B}{d T}\right]_{z=z^{*}} } & =\frac{\rho(1-\alpha) x_{2}}{x_{1}}+\rho\left(\frac{(1-\alpha) T-\alpha^{*} T^{*}}{x_{1}}\right) \frac{d x_{2}}{d T}+\frac{\partial B}{\partial x_{1}}\left(\frac{d x_{1}}{d T}\right) \\
& =\rho(1-\alpha)-\rho \frac{(1-2 \alpha) T}{d_{2}}-2 \rho T\left(\frac{\rho(1-2 \alpha)\left(1-\frac{2 T}{d_{2}}\right)}{2 d_{1}+4 \rho T}\right)
\end{aligned}
$$

Simple calculation shows that

$$
\begin{aligned}
{\left[\frac{d B}{d T}\right]_{z=z^{*}}>0 } & : & T<\left(\frac{1-\alpha}{1-2 \alpha}\right)\left(\frac{d_{2}}{1-\rho d}\right) \\
& =0 \quad: & T=\left(\frac{1-\alpha}{1-2 \alpha}\right)\left(\frac{d_{2}}{1-\rho d}\right) \\
<0 & : & T>\left(\frac{1-\alpha}{1-2 \alpha}\right)\left(\frac{d_{2}}{1-\rho d}\right),
\end{aligned}
$$

So a candidate tax equilibrium is 


$$
\bar{T}=\bar{T}^{*}=\left\{\begin{array}{rll}
\left(\frac{1-\alpha}{1-2 \alpha}\right)\left(\frac{d_{2}}{1-\rho d}\right) & \text { for } & d_{2}<\frac{(1-\rho d)(1-2 \alpha)}{1-\alpha} \\
1 & \text { for } & d_{2} \geq \frac{(1-\rho d)(1-2 \alpha)}{1-\alpha}
\end{array}\right.
$$

Following the definition of the candidate equilibrium, the tax pair $\bar{T}=\bar{T}^{*}$ is increasing with $\alpha=\alpha^{*}$. This is because revenue sharing induces regions to internalize the fiscal externality. Indeed, from the above expression we obtain that there exists a critical tax share $a=1-\frac{1}{2-\frac{d_{2}}{1-\rho d}}<\frac{1}{2}$ such that for any $\alpha=\alpha^{*} \geq a, \bar{T}=\bar{T}^{*}=1$, that is, the mobility problem is fully neutralized by revenue sharing.

Thus inter-regional transfers are desirable as argued by most of the literature on fiscal federalism and a central planner would organize them. ${ }^{9}$ The question, now, is whether there can be made voluntarily by regions, that is, whether there are sustainable as a Nash equilibrium.

Given the triple $\left(T, T^{*}, \alpha^{*}\right)$, differentiating $B\left(T, T^{*}, \alpha, \alpha^{*}\right)$ with respect to $\alpha$ around $z=z^{*}$, and using the symmetry of the model gives

$$
\begin{aligned}
{\left[\frac{d B}{d \alpha}\right]_{z=z^{*}} } & =\frac{-\rho T x_{2}}{x_{1}}+\left(\frac{\partial B}{\partial x_{1}}\right)\left(\frac{d x_{1}}{d \alpha}\right) \\
& =-\rho T-(2 \rho T)\left(\frac{-\rho T}{2 \rho T+d_{1}}\right) \\
& =-\rho T\left(1-\frac{2 \rho T}{2 \rho T+d_{1}}\right)<0 .
\end{aligned}
$$

For any $d_{1}>0$ and any $T=T^{*} \in[0,1]$, each region has an incentive to reduce its revenue share. Hence we have

Proposition 1 Inter-regional transfers are not sustainable when set simultaneously with taxes. The unique symmetric Nash equilibrium is characterized by $\bar{\alpha}=\bar{\alpha}^{*}=0$ and $\bar{T}=\bar{T}^{*}=\frac{d_{2}}{1-\rho d}$ (assuming an interior solution for taxes).

It is impossible for one region to benefit from making transfers to another region in order to forestall migration or to limit its extent (unless the poor are perfectly mobile such as in Myers, 1990). Regions can of course use inter-regional transfers to prevent some poor to immigrate and depress domestic benefit levels; but this effect is always dominated by the direct cost of making inter-regional transfers. Then beneficial migration deterring cannot occur and because there are no local risks to share, voluntary

\footnotetext{
${ }^{9}$ For a good review of the arguments, see Boadway and Flatters (1982) or more recently, Inman and Rubinfeld (1996).
} 
inter-regional transfers would never be made. ${ }^{10}$ We now show that even in this most unfavourable context voluntary inter-regional transfers can still be used as a strategic device to affect future tax competition. To see that we must consider a sequential game in which inter-regional transfers are set (and observable) before taxes. In this situation each region can precommit to share revenue so that the other region also chooses higher taxes. As we shall see this strategic effect can make inter-regional transfers sustainable.

\section{Strategic inter-regional transfers}

In this section we assume that regions can commit to inter-regional transfers if they anticipate benefiting from them. This commitment capacity can be due, for example, to some unmodelled repetition of the interaction between regions. This is also representative of the real world. In the EU, for instance, transfers are set through negotiations and members are to some extent committed to them prior to the setting of their tax rates.

We shall consider the following three-stage game:

stage 1: inter-regional transfer choice: $\alpha, \alpha *$

stage 2: tax choice $: T\left(\alpha, \alpha^{*}\right), T^{*}\left(\alpha, \alpha^{*}\right)$

stage 3: residential choice : $x_{1}\left(T, T^{*}, \alpha, \alpha^{*}\right), x_{2}\left(T, T^{*}, \alpha, \alpha^{*}\right)$

\subsection{The poor are immobile}

We first assume that $d_{1} \rightarrow \infty$ so that the poor are effectively immobile and $x_{1}()=.1 / 2$ for all policy choices.

We can now solve the game backwards. Given the policy choices $\left(z, z^{*}\right)$ the residential choice of the rich $x_{2}($.$) is as given in equation (4). Moving$ backwards to stage 2 , given $T^{*}$ and the pair $\left(\alpha, \alpha^{*}\right)$, the tax choice of the West region solves,

$$
\operatorname{Max}_{T \in[0,1]} B\left(T, T^{*}, \alpha, \alpha^{*}\right)
$$

Using (1) and (4) the necessary FOC is

$$
\begin{aligned}
\frac{d B}{d T} & =\frac{\rho(1-\alpha) x_{2}}{x_{1}}+\rho\left(\frac{(1-\alpha) T-\alpha^{*} T^{*}}{x_{1}}\right) \frac{d x_{2}}{d T} \\
& =\rho(1-\alpha)\left(1+\frac{T^{*}-T}{d_{2}}\right)-\frac{\rho(1-\alpha) T}{d_{2}}+\frac{\rho \alpha^{*} T^{*}}{d_{2}}=0 .
\end{aligned}
$$

\footnotetext{
${ }^{10}$ Note that the famous transfer paradox according to which it might be possible for one region to gain, in a welfare sense, from transferring resources to another region cannot arise here because such transfers have no general equilibrium effects on the terms of trade within the context of the model used here.
} 
Therefore the tax response function of the West region is

$$
T\left(T^{*} ; \alpha, \alpha^{*}\right)=\frac{d_{2}}{2}+\left(1+\frac{\alpha^{*}}{1-\alpha}\right) \frac{T^{*}}{2}
$$

and by analogy

$$
T^{*}\left(T ; \alpha, \alpha^{*}\right)=\frac{d_{2}}{2}+\left(1+\frac{\alpha}{1-\alpha^{*}}\right) \frac{T}{2}
$$

The figure below illustrates how inter-regional transfers shift the tax response functions and lead to higher taxes.

$$
\text { [insert figure 1] }
$$

Combining (13) and (14) gives the Nash equilibrium of the stage 2 tax game,

$$
\bar{T}\left(\alpha, \alpha^{*}\right)=\frac{\left(3+\frac{\alpha^{*}}{1-\alpha}\right) d_{2}}{4-\left(1+\frac{\alpha^{*}}{1-\alpha}\right)\left(1+\frac{\alpha}{1-\alpha^{*}}\right)}
$$

and by analogy

$$
\bar{T}^{*}\left(\alpha, \alpha^{*}\right)=\frac{\left(3+\frac{\alpha}{1-\alpha^{*}}\right) d_{2}}{4-\left(1+\frac{\alpha^{*}}{1-\alpha}\right)\left(1+\frac{\alpha}{1-\alpha^{*}}\right)}
$$

It is easily checked that at $\alpha=\alpha^{*}$,

$$
\bar{T}=\bar{T}^{*}=\left(\frac{1-\alpha}{1-2 \alpha}\right) d_{2}
$$

Therefore for any $\alpha<\frac{1-d_{2}}{2-d_{2}}$ we get an interior solution $\bar{T}=\bar{T}^{*}<1$.

Proceeding backwards to the first stage, each region chooses its tax share given the tax share of the other region, anticipating the resulting tax choices $\left(\bar{T}\left(\alpha, \alpha^{*}\right)\right.$ and $\left.\bar{T}^{*}\left(\alpha, \alpha^{*}\right)\right)$, as well as the resulting migration of the rich $\left(x_{2}\left(T, T^{*}\right)\right)$ and transfer levels $\left(B, B^{*}\right)$. So given $\alpha^{*}$, the West region solves

$$
\operatorname{Max}_{\alpha \in\left[0, \frac{1}{2}\right]} B\left(\alpha, \alpha^{*}\right)=\frac{\rho(1-\alpha) \bar{T}\left(\alpha, \alpha^{*}\right) x_{2}(.)+\rho \alpha^{*} \bar{T}^{*}\left(\alpha, \alpha^{*}\right)\left(1-x_{2}(.)\right)}{x_{1}}
$$

In deciding on its tax share $\alpha$, the West region must therefore consider not only the direct effect of its tax share (that is, the direct cost of sharing revenue, $\partial B / \partial \alpha$ ), but also the strategic effect that arises through the induced change in its rival's tax behavior (that is, $d \bar{T}^{*} / d \alpha$ ). Formally, differentiating $B\left(\alpha, \alpha^{*}\right)$ around $\alpha=\alpha^{*}$ and using the envelope theorem $(\partial B / \partial T=0)$ give

$$
\left[\frac{d B}{d \alpha}\right]_{\alpha=\alpha^{*}}=\frac{-\rho \bar{T}\left(\alpha, \alpha^{*}\right) x_{2}(.)}{x_{1}}+\left[\frac{\partial B}{\partial \bar{T}^{*}}\right]\left[\frac{d \bar{T}^{*}}{d \alpha}\right] .
$$


The first term on the right-hand side of (18) is the direct effect from changing $\alpha$; the second term is the strategic effect that arises from the other region's equilibrium response to the change in $\alpha$. Since

$$
\left[\frac{\partial B}{\partial \bar{T}^{*}}\right]_{\alpha=\alpha^{*}}=\rho \alpha+\frac{\rho(1-2 \alpha) \bar{T}}{d_{2}}=\rho>0
$$

the strategic effect on the West region's transfer is positive if $d \bar{T}^{*} / d \alpha>0$. By applying the implicit function theorem to (16) and using (17) we get

$$
\begin{aligned}
{\left[\frac{d \bar{T}^{*}}{d \alpha}\right]_{\alpha=\alpha^{*}} } & =\frac{-(2-\alpha) d_{2}+4(1-\alpha) \bar{T}^{*}}{4(1-\alpha)^{2}-1} \\
& =\frac{\left(2(1-\alpha)^{2}+\alpha\right)(1-\alpha) d_{2}}{(1-\alpha)(1-2 \alpha)^{2}(3-2 \alpha)}>0
\end{aligned}
$$

Plugging (19) and (20) into (18), we get after straightforward manipulations,

$$
\begin{aligned}
{\left[\frac{d B}{d \alpha}\right]_{\alpha=\alpha^{*}} } & =\left[\frac{2(1-\alpha)^{2}+\alpha}{(1-\alpha)(1-2 \alpha)(3-2 \alpha)}-1\right] \rho d_{2}\left(\frac{1-\alpha}{1-2 \alpha}\right) \\
& =\left[4 \alpha^{3}-10 \alpha^{2}+8 \alpha-1\right]\left(\frac{\rho d_{2}}{(1-2 \alpha)^{2}(3-2 \alpha)}\right) .
\end{aligned}
$$

Hence,there exists a critical value $\alpha^{o}=0.15$ such that

$$
\begin{array}{rlll}
{\left[\frac{d B}{d \alpha}\right]_{\alpha=\alpha^{*}}<0} & : \quad \alpha=\alpha^{*}<\alpha^{o} \\
=0 & : & \alpha=\alpha^{*}=\alpha^{o} \\
>0 & : & \alpha=\alpha^{*}>\alpha^{o}
\end{array}
$$

The following figure depicts the expression $\left[\frac{d B}{d \alpha}\right]_{\alpha=\alpha^{*}}$ as a function of $\alpha=\alpha^{*}$.

$$
\text { [insert figure 2] }
$$

Hence we have the following result,

Proposition 2 Suppose that the poor are immobile and regions set their inter-regional transfers before setting taxes, then there exist three (perfect) Nash equilibria with the following features:

(A) Efficient inter-regional transfers: $\bar{\alpha}=\bar{\alpha}^{*}=\frac{1-d_{2}}{2-d_{2}}$ and $\bar{T}=\bar{T}^{*}=1$.

(B) Partial inter-regional transfers: $\bar{\alpha}=\bar{\alpha}^{*}=0.15$ and $\bar{T}=\bar{T}^{*}=1.2 d_{2}$. 
(C) No inter-regional transfers: $\bar{\alpha}=\bar{\alpha}^{*}=0$ and $\bar{T}=\bar{T}^{*}=d_{2}$.

Inter-regional transfers bring both a direct cost (the cost of sharing your tax revenue) and a strategic benefit in altering the tax competition in the next stage. This strategic effect is however increasing with the level of interregional transfers, and there exists a critical level of interregional transfers such that below this level the strategic effect is too small for inter-regional tranfers to be made voluntarily. But if inter-regional transfers are high enough, their strategic effect is high and they are self-sustaining. Note that it cannot be profitable for regions to set their revenue share above $\frac{1-d_{2}}{2-d_{2}}$ as taxes are already at a corner solution for this level of revenue sharing, and more revenue sharing would bring about no strategic benefit but only the direct cost. Note also that the interior solution for $\alpha$ is independent of the mobility of the rich $d_{2}$.

\subsection{Mobility of the poor}

The introduction of mobility of the poor brings with it a new channel through which inter-regional transfers can affect regions. The allocation of a larger tax share for the inter-regional transfer will cause the marginal poor in a region to migrate. How this possibility affects the set of potential equilibria will now be investigated. We continue to focus on symmetric equilibria. From Section 3 (in which the mobility of the poor is allowed) we know that for any arbitrary $\alpha=\alpha^{*} \in[0,1 / 2]$, the symmetric tax equilibrium is

$$
\bar{T}=\bar{T}^{*}=\left\{\begin{array}{rll}
\left(\frac{1-\alpha}{1-2 \alpha}\right)\left(\frac{d_{2}}{1-\rho d}\right) & \text { for } & d_{2}<\frac{(1-\rho d)(1-2 \alpha)}{1-\alpha} \\
1 & \text { for } & d_{2} \geq \frac{(1-\rho d)(1-2 \alpha)}{1-\alpha}
\end{array}\right.
$$

Therefore, the mobility of the poor (lower $d_{1}$ which is akin to a higher $\left.d=d_{2} / d_{1}\right)$ mitigates tax competition between regions and leads to higher taxes. This is because the poor chase the rich in equilibrium. If the poor are mobile enough, then by chasing the rich they can fully neutralize the effect of the mobility of the rich and thereby solve the fiscal externality problem. ${ }^{11}$ Hence, there is no need to use inter-regional transfers to alter tax competition (no strategic benefit). On the other hand, if the poor are not mobile enough, then inter-regional transfers can be used as a strategic move to mitigate future tax competition. Voluntary inter-regional transfers can thus be made only if the poor are not too mobile relative to the rich.

Formally, in setting its tax share $\alpha$, the West region must consider not only the direct effect of its tax share (that is, the direct cost of sharing

\footnotetext{
${ }^{11}$ It is easily seen from the equilibrium tax expression that for all $\alpha=\alpha^{*} \in[0,1 / 2]$, $\bar{T}=\bar{T}^{*}=1$ for $\frac{d_{1}}{d_{1}+\rho} \leq d_{2}$.
} 
revenue, $\partial B / \partial \alpha$ ), and the strategic effect that arise in altering its rival's tax behavior (that is, $d \bar{T}^{*} / d \alpha$ ), but also the migration effect (that is, $d x_{1} / d \alpha$ ). Therefore, differentiating $B\left(\alpha, \alpha^{*}\right)$ around $\alpha=\alpha^{*}$ and using the envelope theorem $(\partial B / \partial T=0)$ gives

$$
\begin{aligned}
{\left[\frac{d B}{d \alpha}\right]_{\alpha=\alpha^{*}} } & =\frac{-\rho \bar{T} x_{2}}{x_{1}}+\left(\frac{\partial B}{\partial x_{1}}\right)\left(\frac{d x_{1}}{d \alpha}\right)+\left[\frac{\partial B}{\partial \bar{T}^{*}}\right]\left[\frac{d \bar{T}^{*}}{d \alpha}\right] \\
& =-\rho \bar{T}\left(1-\frac{2 \rho \bar{T}}{2 \rho \bar{T}+d_{1}}\right)+\left[\frac{\partial B}{\partial \bar{T}^{*}}\right]\left[\frac{d \bar{T}^{*}}{d \alpha}\right]
\end{aligned}
$$

It follows that the migration of the poor reduces the direct cost of sharing revenue. The mobility of the poor of course also affect the strategic effect which can no longer be derived explicitely. To investigate the possible equilibria we now turn to numerical simulations. The results of the simulation are given in Table 1 . These describe the generic pattern of findings as $d_{1}$ is increased holding $\rho=1$ and $d_{2}=0.5$ constant.

\section{[insert Table 1]}

As can be seen from the Table, multiple equilibria arise for high values of $d_{1}$ (i.e., poor are not very mobile) and voluntary inter-regional transfers can be made (i.e., $\alpha>0$ is a Nash equilibrium). However, when the poor are very mobile (i.e., for low values of $d_{1}$ ) there is a unique equilibrium. This involves no inter-regional transfers. This is because the poor are mobile enough to counteract the mobility of the rich and there is no gain from using inter-regional transfers at all. Note that for all values of $d_{1}$, the equilibrium with no inter-regional transfers $(\alpha=0)$ is sustained.

These results illustrate that the introduction of mobility of the poor extends the previous analysis in a natural way. Proposition 2 has shown that when the poor are completely immobile there are three (symmetric) perfect Nash equilibria. This is also the case here when $d_{1}$ is sufficiently large. Hence multiple equilibria arise due to insufficient mobility of the poor. In contrast, when the poor are highly mobile there is a unique equilibrium which involves no inter-regional transfers.

\section{Regional asymmetries}

In this section we bring in the possibility of regional asymmetries and analyze how this affects the equilibrium outcome. The introduction of asymmetries is important for both theoretical and empirical reasons. Theoretically they are important because they are the main obstacle to the implementation of the fiscal federalism solution. It is indeed difficult to believe that regional 
authorities with different preferences for taxation would agree to transfer all the their fiscal power to a central authority. Regional asymmetries are also a reality and therefore must be introduced in the analysis if we want to compare the predictions of the model with empirical evidence. We first allow regions to differ in their attractiveness (for some exogenous reasons). Then we allow regions to differ in their preferences for redistribution (say, left-wing versus right-wing regions).

\subsection{Different attractiveness}

Returning to the model of section 4.1, it is possible to explore the consequences of asymmetry in the attractiveness of the regions. To do this we assume that the payoff for a rich individual with preference $x \in[0,1]$ is given by

$$
\begin{aligned}
U_{2}\left(z, z^{*}, x\right) & =(1-T)-d_{2} x+\epsilon \quad \text { in the West region } \\
U_{2}^{*}\left(z, z^{*}, x\right) & =\left(1-T^{*}\right)-d_{2}(1-x) \quad \text { in the East region, }
\end{aligned}
$$

If $\epsilon>0$ the West is more attractive and, other things equal, will be more rich and populous in equilibrium. This asymmetry can be interpreted as location in the West providing a higher income or some non-pecuniary benefit such as climate.

Using this payoff function, the division of the rich between the two regions is given by

$$
x_{2}\left(T, T^{*} ; \epsilon\right)=\frac{1}{2}+\frac{T^{*}-T+\epsilon}{2 d_{2}} .
$$

so $x_{2}()>.1 / 2$ when $T=T^{*}$. Proceeding backwards to stage 2 , given revenue sharing choices $\left(\alpha, \alpha^{*}\right)$, the tax response function of the West region is

$$
T\left(T^{*} ; \alpha, \alpha^{*}\right)=\frac{(1+\epsilon) d_{2}}{2}+\left(1+\frac{\alpha^{*}}{1-\alpha}\right) \frac{T^{*}}{2}
$$

and for the East region,

$$
T^{*}\left(T ; \alpha, \alpha^{*}\right)=\frac{d_{2}}{2}+\left(1+\frac{\alpha}{1-\alpha^{*}}\right) \frac{T}{2}
$$

So difference in attractiveness provokes a parallel shifts in opposite directions of the tax responses (i.e., upwards shift for the more attractive region and downwards shift of the tax response of the less attractive region). Equilibrium taxes are

$$
T=\frac{\left(3+\frac{\alpha^{*}}{1-\alpha}\right) d_{2}+\left(1-\frac{\alpha^{*}}{1-\alpha}\right) \epsilon}{4-\left(1+\frac{\alpha^{*}}{1-\alpha}\right)\left(1+\frac{\alpha}{1-\alpha^{*}}\right)}
$$


and

$$
T^{*}=\frac{\left(3+\frac{\alpha}{1-\alpha^{*}}\right) d_{2}-\left(1-\frac{\alpha}{1-\alpha^{*}}\right) \epsilon}{4-\left(1+\frac{\alpha^{*}}{1-\alpha}\right)\left(1+\frac{\alpha}{1-\alpha^{*}}\right)} .
$$

It can be seen from these expressions that if the two regions shared their revenue equally, so $\alpha=\alpha^{*}$, the tax rate would be higher in the West.

Without symmetry, it is no longer possible to use the method of Section 4.1 to characterize the equilibria. However, it is clear that the two corner solutions of complete sharing and no sharing still remain. To find the interior equilibrium, it is necessary to resort to numerical methods. Some results from doing this are reported in Table 2. These show that as the West becomes more attractive its revenue sharing falls but its tax rises. The reason is that the more attractive region can afford to tax more and so derive less benefit from sharing revenue. The converse happens in the East. We can also easily derive from Table 2 , that the more attractive region transfers more to the less attractive region than it receives from it. Moreover this net transfer is increasing with the difference in attractiveness. Interestingly enough, the more attractive region is also paying higher benefits to its poor residents. The greater the difference in attractiveness, the larger the difference in benefits levels.

\section{[Insert Table 2]}

It is interesting to compare these theoretical predictions with data from the European Union (EU). ${ }^{12}$ Countries within the union pay an agreed share of tax revenues to the centre and the aggregate revenue is then redistributed to the member states. Interpreted in terms of our model, the EU is not at a corner solution: revenue sharing occurs but much less than $1 / 2$ of each countries tax revenue. Therefore, we should relate the data to the comparative statics of the asymmetric interior equilibrium described in Table 2.

To do this, we use GDP/head in the member states as a measure of attractiveness. In Table $3 a$ this is graphed against revenue from direct taxes as a proportion of GDP which we interpret as capturing the meaning of $T$. The prediction of the model is that the tax rate should rise as GDP/head rises. This is very clearly the pattern observed in Table $3 \mathrm{a}$. Table $3 \mathrm{~b}$ considers the revenue sharing aspect. In this table, GDP/head is graphed against each member state's contribution to the EU budget as a proportion of its total tax revenue. We interpret this to be $\alpha$. The prediction of the model

\footnotetext{
${ }^{12}$ The sources for the data are: (1) 10th Annual Report of the Structural Funds Commission of the European Communities, 1999, COM(1999) 467 final; (2) Official Journal of the European Communities, C349, vol.42, December 1999; (3) European Economy, European commission Directorate-General for Economic and Financial Affairs, no.69, 1999.
} 
is that $\alpha$ should fall as GDP/head rises. Once again, this is exactly what is observed in the table.

While these results cannot prove that the model is correct, their agreement with the theoretical predictions is suggestive that something like the mechanism we describe may be at work in the determination of EU policy. This is clearly an issue worthy of further analysis.

[Insert Tables 3a and 3b]

\subsection{Different preference for redistribution}

Regional difference in the redistribution motive would translate in different regional decision rules. Consider that the decision rule in the West is

$$
\operatorname{Max}_{\{\alpha, T\}} B\left(T, T^{*}, \alpha, \alpha^{*}\right)+\lambda(1-T)
$$

and in the East,

$$
\operatorname{Max}_{\left\{\alpha^{*}, T^{*}\right\}} B^{*}\left(T, T^{*}, \alpha, \alpha^{*}\right)+\lambda^{*}\left(1-T^{*}\right)
$$

where $\lambda$ and $\lambda^{*}$ (with $0 \leq \lambda, \lambda^{*}<1$ ) are the weights given to the income of the rich in the West and East, respectively. If $\lambda<\lambda^{*}$, the West has a stronger preference for redistribution and, other things equal, will tax more in equilibrium. Obviously the division of the rich between the two regions is only indirectly affected by this asymmetry through its effect on tax choices. So, $x_{2}=1 / 2$ whenever $T=T^{*}$. Given revenue shares $\left(\alpha, \alpha^{*}\right)$ the tax response function in the West is,

$$
T\left(T^{*} ; \alpha, \alpha^{*}\right)=\left[\frac{d_{2}}{2}-\frac{d_{2} \lambda}{2(1-\alpha) \rho}\right]+\left(1+\frac{\alpha^{*}}{1-\alpha}\right) \frac{T^{*}}{2}
$$

and in the East,

$$
T^{*}\left(T ; \alpha, \alpha^{*}\right)=\left[\frac{d_{2}}{2}-\frac{d_{2} \lambda^{*}}{2\left(1-\alpha^{*}\right) \rho}\right]+\left(1+\frac{\alpha}{1-\alpha^{*}}\right) \frac{T}{2}
$$

A lower redistribution motive in the East induces a parallel shift downwards of the tax response in the East, but also because of the strategic complementarity in taxes, reduces tax rate in the West. This illustrates how a Left-wing government competing with a Right-wing government may have to cut its tax rate. It is also easily seen from these tax responses, that if the two regions share their revenue equally, $\alpha=\alpha^{*}$, the tax rate would be higher in the West when $\lambda<\lambda^{*}$. 
Given the pair $\left(\lambda, \lambda^{*}\right)$, the Nash equilibrium in stage 2 subgame is

$$
\bar{T}\left(\alpha, \alpha^{*}\right)=\frac{\left(3+\frac{\alpha^{*}}{1-\alpha}\right) d_{2}}{4-\left(1+\frac{\alpha^{*}}{1-\alpha}\right)\left(1+\frac{\alpha}{1-\alpha^{*}}\right)}-\frac{\left[\frac{2 \lambda d_{2}}{\rho(1-\alpha)}+\frac{\lambda^{*} d_{2}}{\rho\left(1-\alpha^{*}\right)}\left(1+\frac{\alpha^{*}}{1-\alpha}\right)\right]}{4-\left(1+\frac{\alpha^{*}}{1-\alpha}\right)\left(1+\frac{\alpha}{1-\alpha^{*}}\right)}
$$

and,

$$
\bar{T}^{*}\left(\alpha, \alpha^{*}\right)=\frac{\left(3+\frac{\alpha}{1-\alpha^{*}}\right) d_{2}}{4-\left(1+\frac{\alpha^{*}}{1-\alpha}\right)\left(1+\frac{\alpha}{1-\alpha^{*}}\right)}-\frac{\left[\frac{2 \lambda^{*} d_{2}}{\rho\left(1-\alpha^{*}\right)}+\frac{\lambda d_{2}}{\rho(1-\alpha)}\left(1+\frac{\alpha}{1-\alpha^{*}}\right)\right]}{4-\left(1+\frac{\alpha^{*}}{1-\alpha}\right)\left(1+\frac{\alpha}{1-\alpha^{*}}\right)}
$$

The first term of these two expressions is the same as in (15) and (16). The second term reflects the effect of asymmetric preference for redistribution.

To derive the optimal choices of revenue sharing we must resort to numerical method. The results are reported in Table 4. These results show that the region who cares less about redistribution shares less revenue but suprisingly taxes almost the same. Revenue sharing acts as a buffer that absorbs almost completely the differences in the preference for redistribution. As both regions care less about redistribution, they share more revenue again with few effect on their tax rates. This may explain why in the EU context, left-wing and right-wing governments can impose similar taxes but choose very different revenue shares. Tax harmonization can thus be reconciled with political disintegration if member states can negotiate different inter-regional transfers.

[Insert Table 4]

\section{Conclusion}

In this paper we have shown that inter-regional transfers are desirable and can be sustained as a Nash equilibrium. Remarkably this is true irrespective of regional asymmetries. It is also shown that the predictions of our model fit well with empirical evidence. In contrast to the existing literature, interregional transfers are not used to purchase the optimal population (like in Myers, 1990) or for risk sharing (like in Lockwood, 1999) but rather because of their strategic effects. In deciding on their inter-regional transfers, regions can soften future tax competition. These strategic interregional transfers of course are effective only if regions can credibly commit to them before setting their taxes on the mobile factors. But since this strategic move brings a better outcome to all regions (compared to the simultaneous game without such strategic move), it is also well known that their credibility is questionable. Therefore, an important issue to consider is how regions can acquire this credibility. 
Acknowledgements. The authors thank for useful comments and discussions participants to the 2000 Summer Workshop at Stanford University and the International Conference on Public Economic Theory at the University of Warwick as well as seminar participants at QMW and Keele University.

\section{References}

[1] Bucovestky, S., M. Marchand, P. Pestieau, 1998, Revelation of tastes for a public good in a federation, Journal of Urban Economics

[2] Boadway, R. and F. Flatters, 1982, Efficiency and equalization payments in a federal system of government : a synthesis and extension of recent results, Canadian Journal of Economics, 15, 613-33.

[3] Caplin, A., B. Nalebuff, 1997, Competition among Institutions, Journal of Economic Theory, 72, 306-42.

[4] Cremer, H., V. Fourgeaud, M. Monteiro, M. Marchand, and P. Pestieau, 1996, Mobility and redistribution : a survey, Public Finance/Finances Publiques, 51, 325-52.

[5] Epple, D. and T. Romer, 1991, Mobility and redistribution, Journal of Political Economy, 99, 828-58.

[6] Hansen, N., A. Kessler,, 1998, A positive theory of inter-regional redistribution and constitutional choice, Unpublished paper, University of Bonn.

[7] Hindriks, J., 1999, The consequences of labour mobility for redistribution: tax versus transfer competition, Journal of Public Economics, 74, $215-34$.

[8] Inman, R., and D. Rubinfeld, 1996, Designing tax policy in federalist economies: an overview, Journal of Public Economics, 60, 307-334.

[9] Kirchgassner, G and W. Pommerehne, 1996, Tax harmonisation and tax competition in the European Union: Lessons from Switzerland, Journal of Public Economics, 60, 351-71.

[10] Konishi, H., M. Lebreton and S. Weber, 1998, Equilibrium in a finite local public goods economy, Journal of Economic Theory, 79, 224-44.

[11] Lockwood, B., 1999, Inter-regional insurance, Journal of Public Economics, $72,1-38$.

[12] Mansoorian, A., and G.M. Myers, 1993, Attachment to home and efficient purchases of population, Journal of Public Economics, 52, 117-32. 
[13] Moffitt, R., 1992, Incentive effects of the U.S. welfare system : a review, Journal of Economic Literature, 30, 1-61.

[14] Myers, G., 1990, Optimality, free mobility, and the regional authority in a federation, Journal of public Economics, 43, 107-21.

[15] Oates, W., 1972,Fiscal Federalism, Harcourt Brace: New York.

[16] Pauly, M.V., 1973,income redistribution as a local public good, Journal of Public Economics, 2, 35-58.

[17] Piketty, T., 1996, A federal voting mechanism to solve the fiscalexternality problem, European Economic review, 40, 3-17.

[18] Wellisch, D., 1994, interregional spillovers in the presence of perfect and imperfect household mobility, Journal of Public Economics, 55, 167-84.

[19] Wildasin, D. E., 1991, Income redistribution in a common labor market, American Economic Review, 81, 757-73.

[20] Wildasin, D.E., 1994, Income redistribution and migration, Canadian Journal of Economics, 27, 637-56.

[21] Wooders, M. H., 1978,Equilibria, the core, and regional structures in economies with a local public good , Journal of Economic Theory, 18, $328-48$. 


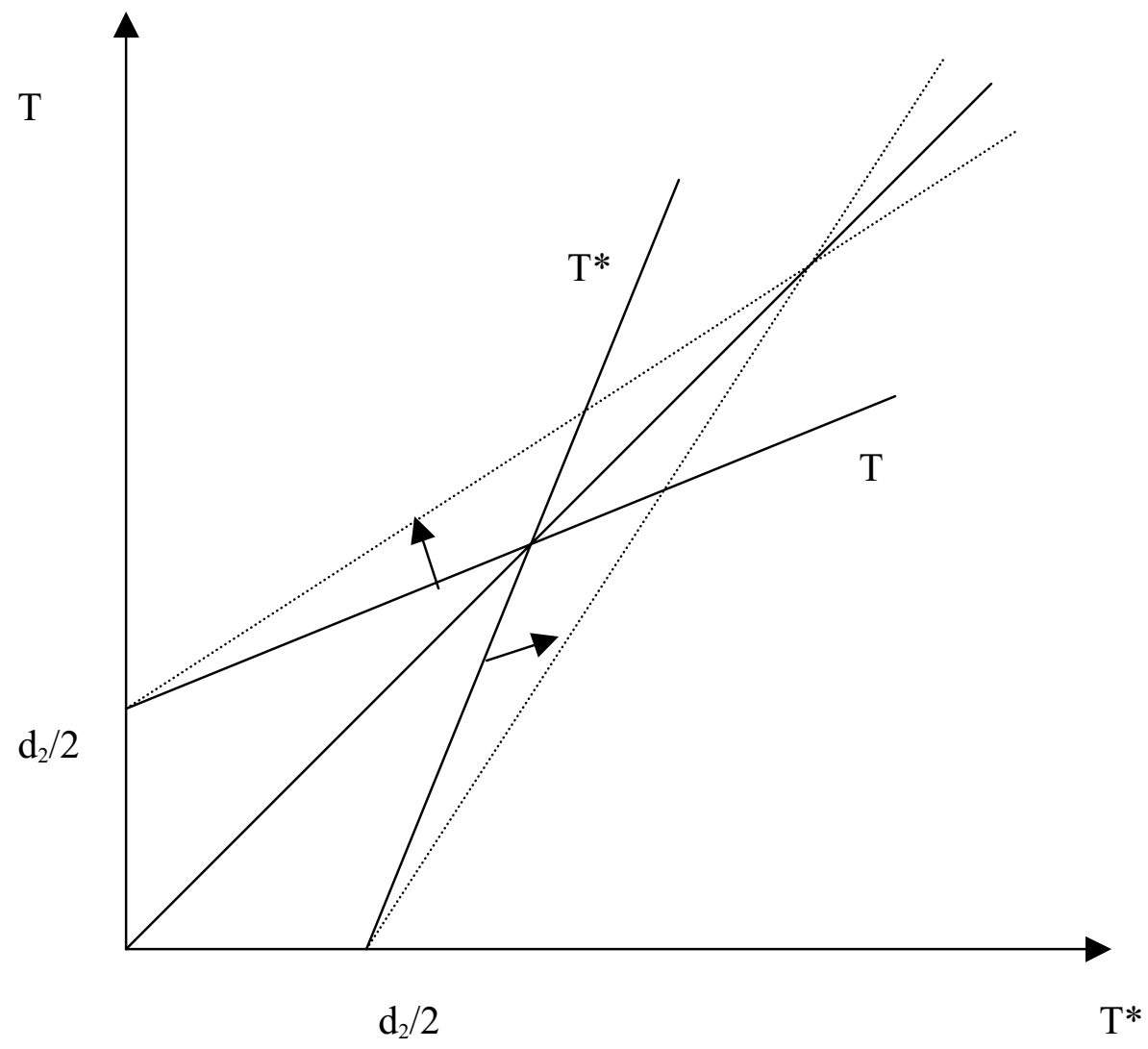

Figure 1: Effect of inter-regional transfers on equilibrium taxes 


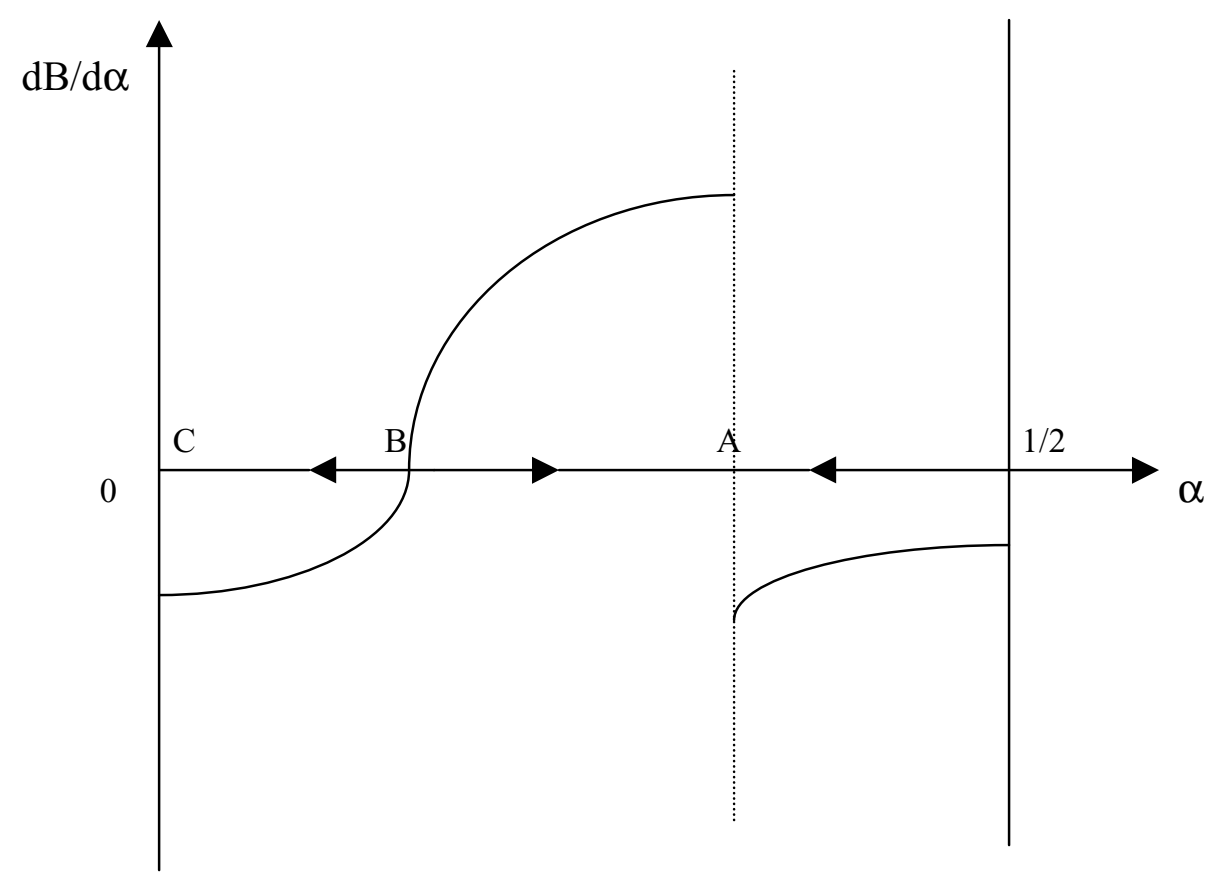

Figure 2: Multiple Equilibria 


\begin{tabular}{|l|ll|ll|ll|}
\hline $\mathrm{d}_{1} \leq 3$ & $\alpha=0$ & $\mathrm{~T}=1$ & & & & \\
\hline $\mathrm{d}_{1}=4$ & $\alpha=0$ & $\mathrm{~T}=0.571$ & $\alpha=0.05$ & $\mathrm{~T}=0.603$ & $\alpha=0.5$ & $\mathrm{~T}=1$ \\
\hline $\mathrm{d}_{1}=10$ & $\alpha=0$ & $\mathrm{~T}=0.526$ & $\alpha=0.11$ & $\mathrm{~T}=0.600$ & $\alpha=0.5$ & $\mathrm{~T}=1$ \\
\hline $\mathrm{d}_{1}=100$ & $\alpha=0$ & $\mathrm{~T}=0.502$ & $\alpha=0.15$ & $\mathrm{~T}=0.601$ & $\alpha=0.5$ & $\mathrm{~T}=1$ \\
\hline
\end{tabular}

Table 1: Equilibria for various degrees of mobility of the poor and $d_{2}=0.5, \rho=1$. 


\begin{tabular}{|c|c|c|c|c|}
\hline$\varepsilon=0$ & $\begin{array}{l}\alpha=0.152 \\
\alpha^{*}=0.152\end{array}$ & $\begin{array}{l}T=0.244 \\
T^{*}=0.244 \\
x=0.5\end{array}$ & $\begin{array}{l}B=0.244 \\
B^{*}=0.244\end{array}$ & $\begin{array}{l}\alpha T x \quad=0.019 \\
\alpha^{*} T^{*}(1-x)=0.019 \\
\text { net transfer }=0\end{array}$ \\
\hline 0.1 & $\begin{array}{l}\alpha=0.129 \\
\alpha^{*}=0.174\end{array}$ & $\begin{array}{l}T=0.275 \\
T^{*}=0.209 \\
x=0.584\end{array}$ & $\begin{array}{l}B=0.310 \\
B^{*}=0.185\end{array}$ & $\begin{array}{l}\alpha T x \quad=0.021 \\
\alpha^{*} T^{*}(1-x)=0.015 \\
\text { net transfer }=0.006\end{array}$ \\
\hline 0.2 & $\begin{array}{l}\alpha=0.105 \\
\alpha^{*}=0.196\end{array}$ & $\begin{array}{l}T=0.305 \\
T^{*}=0.172 \\
x=0.668\end{array}$ & $\begin{array}{l}B=0.387 \\
B^{*}=0.135\end{array}$ & $\begin{array}{l}\alpha T x \quad=0.021 \\
\alpha^{*} T^{*}(1-x)=0.011 \\
\text { net transfer }=0.010\end{array}$ \\
\hline 0.3 & $\begin{array}{l}\alpha=0.080 \\
\alpha^{*}=0.216\end{array}$ & $\begin{array}{l}T=0.332 \\
T^{*}=0.133 \\
x=0.752\end{array}$ & $\begin{array}{l}B=0.474 \\
B^{*}=0.092\end{array}$ & $\begin{array}{l}\alpha T x \quad=0.020 \\
\alpha * T^{*}(1-x)=0.007 \\
\text { net transfer }=0.013\end{array}$ \\
\hline 0.4 & $\begin{array}{l}\alpha=0.054 \\
\alpha^{*}=0.234\end{array}$ & $\begin{array}{l}T=0.357 \\
T^{*}=0.091 \\
x=0.835\end{array}$ & $\begin{array}{l}B=0.571 \\
B^{*}=0.055\end{array}$ & $\begin{array}{l}\alpha T x \quad=0.016 \\
\alpha^{*} T^{*}(1-x)=0.003 \\
\text { net transfer }=0.013\end{array}$ \\
\hline
\end{tabular}

Table 2. Asymmetric attractiveness (with $d_{1}=\infty, d_{2}=0.2$ and $\rho=1$ ) 
Table 3a. Tax and GDP/head

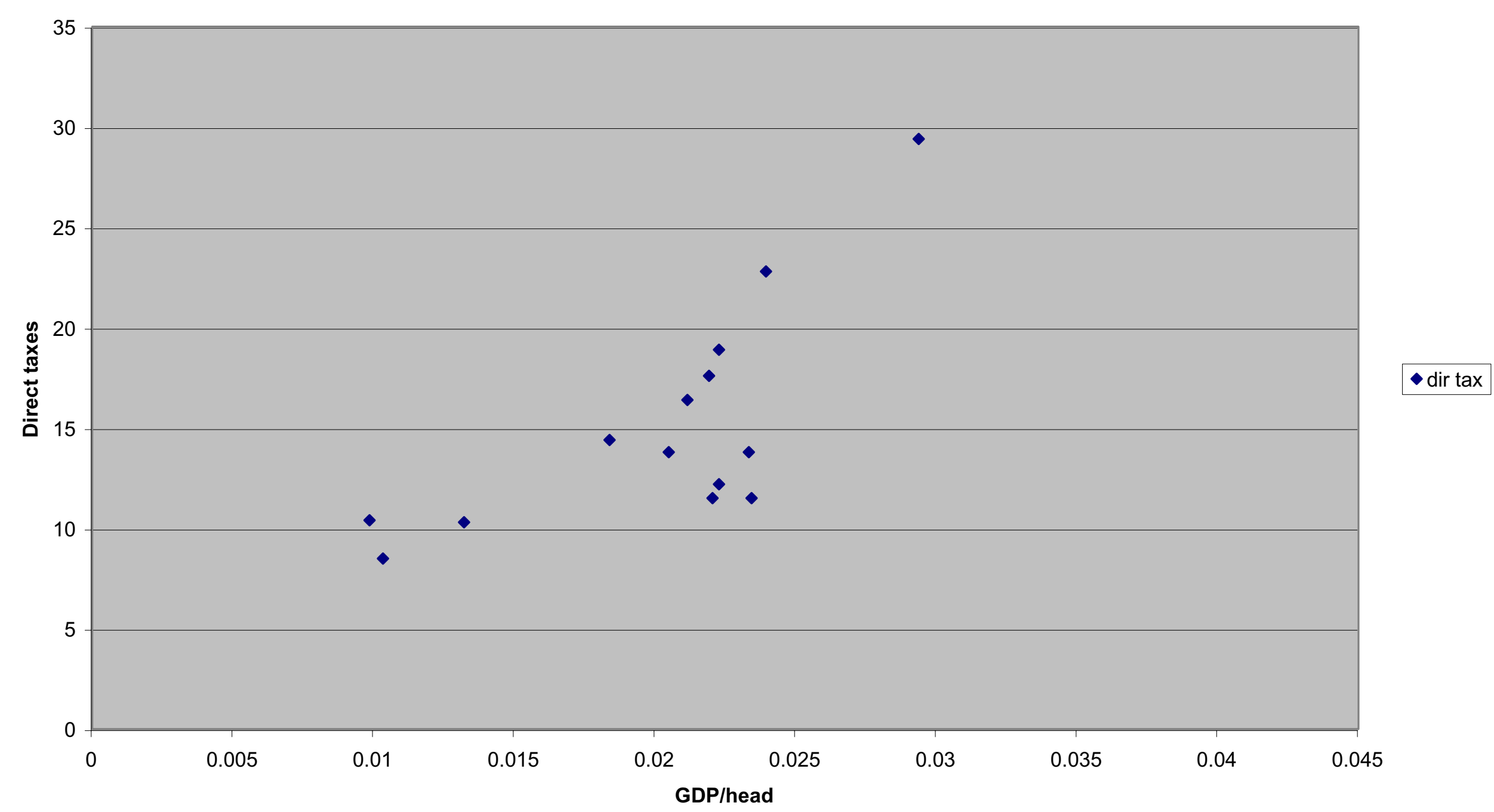


Table 3b. Revenue share (alpha) and GDP/head

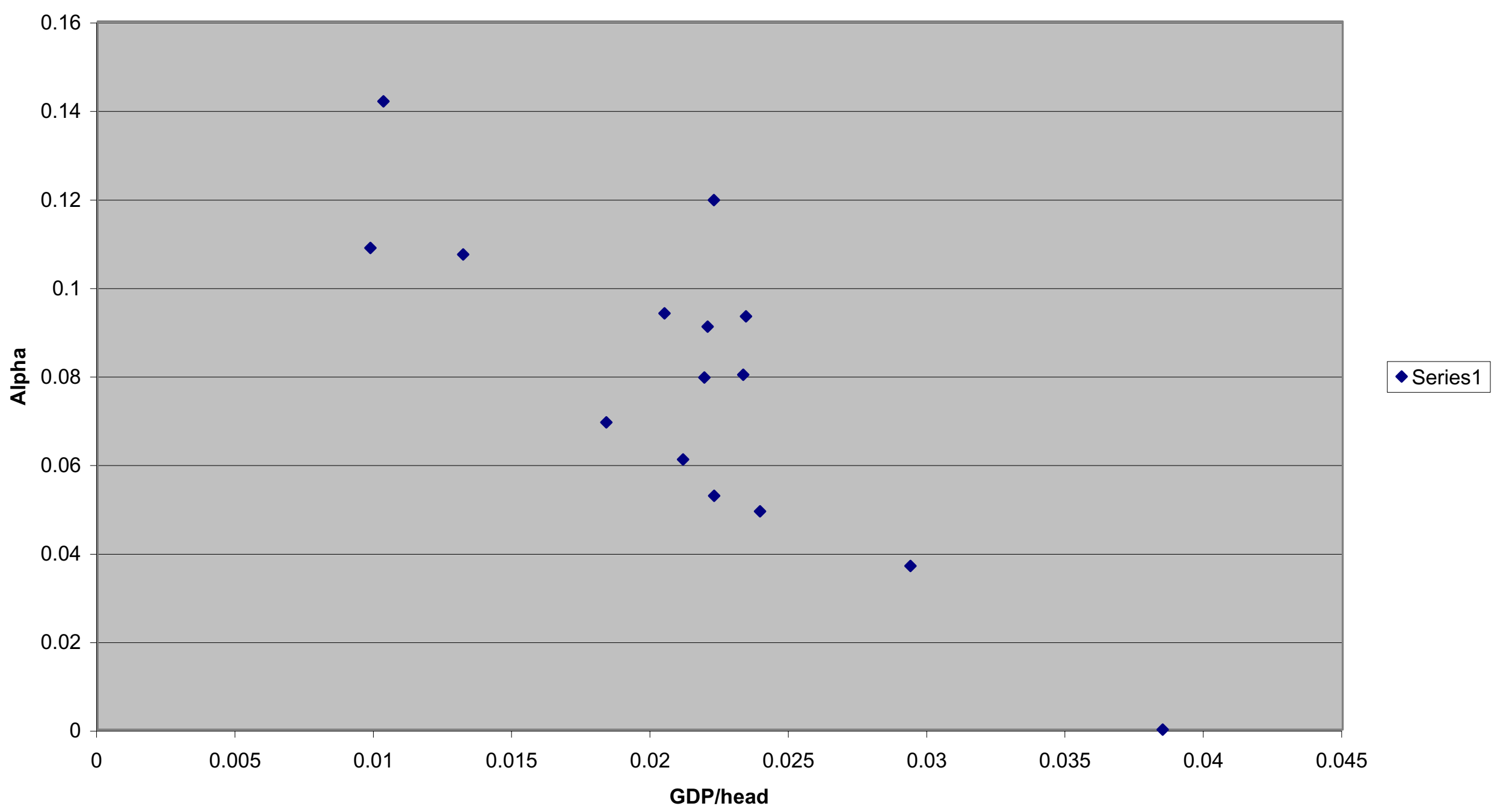




\begin{tabular}{|c|c|c|c|c|c|}
\hline$\lambda *$ & $\lambda$ & 0 & 0.1 & 0.2 & 0.3 \\
\hline 0 & & $\begin{array}{l}\alpha=0.152 \\
T=0.609 \\
\alpha^{*}=0.152 \\
T^{*}=0.609\end{array}$ & $\begin{array}{l}\alpha=0.151 \\
T=0.605 \\
\alpha^{*}=0.220 \\
T^{*}=0.611\end{array}$ & $\begin{array}{l}\alpha=0.150 \\
T=0.608 \\
\alpha^{*}=0.296 \\
T^{*}=0.619\end{array}$ & $\begin{array}{l}\alpha=0.146 \\
T=0.603 \\
\alpha^{*}=0.360 \\
T^{*}=0.620\end{array}$ \\
\hline & & & $\begin{array}{l}\alpha=0.220 \\
T=0.607 \\
\alpha^{*}=0.220 \\
T^{*}=0.607\end{array}$ & $\begin{array}{l}\alpha=0.218 \\
T=0.603 \\
\alpha^{*}=0.289 \\
T^{*}=0.609\end{array}$ & $\begin{array}{l}\alpha=0.215 \\
T=0.602 \\
\alpha^{*}=0.361 \\
T^{*}=0.613\end{array}$ \\
\hline 0.2 & & & & $\begin{array}{l}\alpha=0.288 \\
T=0.604 \\
\alpha^{*}=0.288 \\
T^{*}=0.604\end{array}$ & $\begin{array}{l}\alpha=0.286 \\
T=0.601 \\
\alpha^{*}=0.360 \\
T^{*}=0.607\end{array}$ \\
\hline 0.3 & & & & & $\begin{array}{l}\alpha=0.358 \\
T=0.602 \\
\alpha^{*}=0.358 \\
T^{*}=0.602\end{array}$ \\
\hline
\end{tabular}

Table 4. Asymmetric preference for redistribution 